\title{
HUET, NAHAYEILLI BEATRIZ JUÁREZ. UN PEDACITO DE DIOS EN CASA. MÉXICO, D.F.: CIESAS, 2014.
}

Hugo José Suárez

\section{EL INICIO}

Mario Vargas Llosa tiene un magnífico pasaje donde cuenta como, en su adolescencia, vibró con el ritmo de mambo:

'Para uno de esos carnavales llegó Dámaso Pérez Prado con su orquesta. El mambo, recientísima invención caribeña, hacía furor también en Lima y hasta se había convocado un campeonato nacional de mambo en la plaza de Acho, que el arzobispo, monseñor Guevara, prohibió con amenaza de excomunión a los participantes. La llegada de Pérez Prado repletó el aeropuerto, y ahí estuve yo también con mis amigos, corriendo detrás del auto descubierto, que llevaba al hotel Bolívar, saludando a diestra y siniestra, al compositor de El ruletero y del Mambo número cinco' (LLOSA, Vargas Mario. El pez en el agua. Barcelona: Ed. Seix Barral, 1993. p. 67.)

En ese párrafo vemos la expansión de las "industrias culturales" sobre las cuales reposa la santería que llegaron, ya en aquellos años, a varios rincones latinoamericanos. Pero claro, la naturaleza de la literatura no está en explicar y comprender el por qué las experiencias vividas, sino en presentarlas haciendo gala del relato. Para los científicos sociales, tal episodio abriría una serie de preguntas, preguntas que, desde otro tiempo y espacio, Nahayeilli Juárez pone sobre la mesa en su libro Un pedacito de Dios en casa.

1 Professor e pesquisador titular do Instituto de Investigaciones Sociales da Universidad Nacional Autónoma de México. Contato: hugojose@unam.mx

Debates do NER, Porto Alegre, ano I6, N. 27, P. 45I-457, JAn./Jun. 2015 
Con una agradable narración personal, la antropóloga cuenta cómo se encontró con su objeto de estudio. La inquietud la traía años antes luego de un seminario sobre África en la Facultad de Ciencias Políticas y Sociales de la UNAM mientras cursaba la carrera de Relaciones Internacionales. Con su primer viaje al continente africano, entonces estudiante de licenciatura, se fue gestando una curiosidad que luego se materializaría como tema de investigación doctoral; Nahayeilli quedó atrapada en las redes de la santería, a quien dedicó largos años de su vida académica. Un lustro más tarde, cursando el posgrado en El Colegio de Michoacán, llamó a su antiguo maestro quien le presentó a uno de sus primeros “informantes”. El primer descubrimiento fue que no tendría que hacer viajes intercontinentales para su estudio, pues en la ciudad de México "había tremendos santeros". Fue a la casa de aquel estudiante para abonar sus sorpresas:

En un rincón, sobre el piso, se encontraba todo esto: un caldero con varios objetos de metal dentro - entre otros, sobresalían una escalera, una pala, un pico, un azadón, un yunque, un machete, un arco y una flecha pequeños -; junto, dos platos de barro - en cada uno había sido colocada una piedra; una de ellas tenía cauris incrustados que le dibujaban un rostro -; un sombrerito de paja y dulces alrededor. 'Este es mi Elaguá-Eshu - exclamó Pepe -. ElaguáEshu siempre va en el piso, es el contacto con la tierra y debe estar siempre en cazuelas de barro' (p. 16).

La invitación analítica estaba consolidada. De ahí nacieron las preguntas de investigación y una larga agenda de trabajo:

[...] ¿qué factores estaban propiciando la divulgación y presencia de la santería en México? ¿Se trataba de un fenómeno reciente o no? ¿Cuáles eran los motivos por los que una persona optaría por la santería como práctica religiosa? ¿Qué elementos la hacían atractiva o singular en un contexto predominantemente católico? (p. 17). 


\section{EL LIBRO}

El largo documento que hoy sale a la luz, resultado de años de intenso trabajo y una tesis de doctorado, recoge la múltiple información y la presenta en un formato que respeta las reglas de una investigación científica. En la introducción arma el problema y traza la ruta a seguir. El capítulo primero, Marco teórico-metodológico, expone los conceptos fundamentales que le permitirán profundizar en su estudio teniendo claro lo que busca. Habla así de la globalización y la transnacionalización, de lo global y lo local, de la red, el capital social y los marcos interpretativos. Del capítulo segundo al sexto, la autora nos invita a detenernos en los múltiples rostros de la santería, leída, por supuesto, por su intención analítica. Así, el segundo y el tercero muestran su expansión en México, apoyados en la amplia paleta de industrias culturales. La música, el cine, luego la televisión, la radio y más, fueron los canales cómo, en un primer momento, la santería se expandió como cultura, apoyada en las "diosas y rumberas exóticas", navegando entre las aguas de lo desconocido y lo atractivo con igual eficacia. La transnacionalización de la santería tuvo etapas, tiempos, formas, personajes, que fueron recibidas con igual ritmo en la Ciudad de México. Es ahí donde se da cuenta de la diversidad y complejidad de los canales de divulgación, no articulada al estilo de la evangelización católica, pero con una eficacia remarcable. El capítulo cuatro, Nahayeilli muestra las lógicas de organización de las redes sobre las cuales se montó esta oferta religiosa. En el quinto se introduce en las trayectorias espirituales de los santeros y muestra, paso a paso, cómo se deviene un babalawo mexicano. En el capítulo sexto se discute la tensión entre el estigma y la legitimidad en el campo religioso capitalino, desglosando desde las campañas de satanización por parte del mundo católico vinculando santería con narcotráfico, delincuencia y violencia, hasta las estrategias de legitimación en un ámbito adverso. Finalmente, el último capítulo muestra la transnacionalización y el vaivén entre tensiones y alianzas. Se cierra con las conclusiones y con sugerentes anexos, entre ellos fotos, gráficos y cuadros, que bien podrían entrar en el cuerpo mismo del libro.

Debates do NER, Porto Alegre, ano I6, N. 27, P. 45I-457, JAn./Jun. 2015 


\section{LA DISCUSIÓN TEÓRICA}

Desde la introducción, la autora dice lo que es parte del corazón de la discusión teórica. En las ciencias sociales de la religión en México se había estudiado de distintas maneras la "conversión", los "buscadores espirituales", la "movilidad religiosa", la "diversidad religiosa", etc. pero todavía hay un desafío teórico para entender cómo los individuos construyen su sentido religioso acudiendo a distintas tradiciones. Así lo plantea:

[...] más que una combinación de religiones, lo que observamos en el terreno de estudio es una 'cohabitación religiosa', o bien, una cohabitación mística neoesotérica, es decir, la coexistencia de prácticas y de elementos tomados de diversos sistemas de creencia. Estos no son mutuamente excluyentes, al menos desde la perspectiva del creyente, y su heterogeneidad está dada por el carácter selectivo del sujeto y su capacidad de articularlos y complementarlos, más que de combinarlos. Asimismo, encontré que no hay un abandono total de las creencias previas cuando se adoptan las nuevas; éstas no sustituyen a las anteriores, tampoco se da siempre una verdadera transformación de las creencias. El individuo no parte, pues, de una tabla rasa, sino que, de acuerdo con su propia trayectoria y con su experiencia espiritual, hace un ejercicio de reinterpretación y reapropiación de prácticas religiosas y elementos de sistemas de creencias distintos, haciendo posible que subsistan, coexistan e incluso se modifiquen. En realidad, bajo el término genérico de santería, se agrupan de manera complementaria el espiritualismo kardeciano, el Palo Monte y el catolicismo popular, un universo que se constituyó como tal desde Cuba. A menudo, a esta complementariedad se le suman el espiritualismo trinitario mariano, el espiritismo, algunas prácticas de la medicina tradicional indígena, creencias y prácticas esotéricas, neoesotéricas, neomágicas y aquellas pertenecientes a la sensibilidad propia del new age (p. 20-21).

Este largo párrafo nos introduce a una compleja tensión, que atraviesa todo el texto, respecto a lo que se toma, lo que se inventa, lo que se reproduce en esta experiencia religiosa contemporánea. Para el caso de la santería, la autora explica que en México parte de su éxito se debe a la interacción con 
[...] dos marcos culturales que [...] fungen como factores propulsores de su divulgación y también de su apropiación muchas veces complementaria. Por un lado, el de las tradiciones de arraigo prehispánicas y coloniales - yerberos, curanderos, brujos - ligadas a prácticas de catolicismo popular y al espiritualismo mariano; y por el otro, el de las prácticas neoesotéricas, las cuales introducen elementos de culturas orientales y tradiciones esotéricas antiguas que eran bastante ajenas a los mexicanos y que, en los últimos 15 años, han cobrado fuerza y visibilidad en varios puntos del país (p. 138-139).

La santería es entonces la que puede articular estos dos marcos culturales sin ortodoxia, más bien con una flexibilidad estratégica que le permite sobrevivir y expandirse sin un aparato institucional de divulgación.

Lo remarcable de este problema teórico es que la santería muestra lo que sucede en varias de las ofertas religiosas en el país. Como ya lo han dicho varios autores, al interior del catolicismo - tanto popular como liberacionista o conservador -, del protestantismo, del pentecostalismo, y de la amplia paleta de experiencias religiosas, la característica es, unido a la pérdida de eficacia de las instituciones monopolizadoras del sentido religioso, la flexibilidad para producir y reproducir, repetir o inventar nuevos relatos que dotan al creyente de una coherencia en su experiencia, tanto para consigo mismo como para su entorno. Pero no se trata de una reproducción en el aire, posible hasta el infinito o sin límites - como parecería sugerir la teoría del bricolage religioso o de la nebulosa esotérica -, los "marcos culturales" - para retomar las categorías de Juárez - son claros: el catolicismo popular y lo "neoesotérico", donde cabe desde la ecosofía hasta las influencias del new age, las religiones orientales, los seres de luz, y un largo etcétera. A mi entender, el tercer marco cultural de la sociedad mexicana es el racionalismo modernizador, resultado la revolución y del paradigma propio de la modernidad que en México tuvo importante presencia y desde el cual también se construyen formas religiosas de importante anclaje. 


\section{PARA CONCLUIR}

Volvamos al título. Un pedacito de Dios en casa nos habla de una expresión religiosa desinsitucionalizada, o más bien con sus propias formas de construir su institucionalidad. Entre otras cosas, la idea de que Dios puede estar en la casa, y no en el templo o en El Santísimo - como sugería la doctrina católica -, abre las posibilidades de expresión de lo divino y empata con varios estudios, cualitativos y cuantitativos, que muestran que Dios está "en todas partes", "en uno mismo", "en la naturaleza”, "en el cosmos", "en la Virgen", etc. Lo sagrado se ha desterritorializado y ha multiplicado sus posibilidades de aparición y presencia. Eso ocurre en la santería, pero también en otras religiosidades; podríamos decir que es una de las características contemporáneas de representación de lo sagrado.

Por otra parte, el presente estudio no deja de ser sintomático: se trata de una religión que primero se difunde como cultura secular (danza, música, cine) y luego asume un rostro más claramente religioso. Parecería ser un caso poco común, pues normalmente el proceso es inverso; aunque deja sobre la mesa la pregunta sobre cuál será el futuro de manifestaciones culturales de los medios masivos de comunicación (por ejemplo películas como El Señor de los Anillos, la Guerra de las Galaxias, Harry Potter, etc.). ¿Seguirán éstas la misma ruta e inspirarán nuevas religiones? Difícil saberlo, pero queda la duda.

Finalmente, en términos metodológicos, es muy sugerente no sólo el amplio, profundo e inteligente trabajo etnográfico sino, además, la compleja reflexión respecto del involucramiento o no con el objeto estudiado. Juárez no oculta las dificultades de acercarse a un tema delicado que, por su naturaleza, guarda una serie de secretos que los actores no siempre desean compartir, menos con un foráneo. ¿Había que convertirse en santera para poder tener conocimiento profundo del tema? No, responde Nahayeilli, pero no es fácil investigar tratando de administrar equilibradamente involucramiento y distancia. Esa reflexión, que a menudo queda fuera de los escritos, la autora nos comparte con franqueza y generosidad.

Debates do NER, Porto Alegre, ano i6, N. 27, P. 45I-457, JAn./Jun. 2015 
El libro llena un vacío sobre una experiencia prácticamente no estudiada que dinamiza el campo religioso mexicano. Por ello, está convocado a ser una referencia ineludible para estos estudios, quedará mucho tiempo entre nosotros y estaremos esperando las nuevas "empresas etnográficas por emprender”, palabras con las cuales la autora cierra su estudio.

\section{REFERENCIAS}

HUET, Nahayeilli Beatriz Juárez. Un pedacito de Dios en casa. México, D.F.: CIESAS, 2014.

LLOSA, Mario Vargas. El pez en el agua. Barcelona: Ed. Seix Barral, 1993. p. 67.

Recebido em: 15/12/2014

Aprovado em: 03/01/2015 